\title{
TRANSFORMATIVE LEARNING IN A CONTEXT OF DEEP DIVISION: THE IMPORTANCE OF LEARNING ABOUT SELF FOR LEADERSHIP
}

\author{
V.S. Spooner \\ Gordon Institute of Business Science \\ University of Pretoria \\ Pretoria, South Africa \\ e-mail: spoonerv@gibs.co.za / https://orcid.org/0000-0003-2635-8070
}

\author{
V. M. John \\ University of KwaZulu-Natal \\ Pietermaritzburg, South Africa \\ e-mail: JohnV@ukzn.ac.za / https://orcid.org/0000-0001-5991-5019
}

\section{ABSTRACT}

Leadership training at institutions of higher learning typically foreground theories of leadership, predominantly as taught content. These programmes, however, are not premised on a context of deep division, inequality and hurt. Understanding this context is crucial for leading change in postapartheid South Africa. The UP GIBS Nexus Leadership Programme uses an innovative and transformative pedagogy for leadership training. This represents an alternative paradigm because the programme prioritises learning about oneself and one's beliefs over a taught curriculum. This leadership programme was specifically designed to equip leaders for the post-apartheid South African context. This article discusses findings from a qualitative study of the Nexus Leadership Programme which reveal profound learning at a personal level and an undoing of perspectives garnered from South Africa's divided past. Data were collected from programme participants and programme managers, and reflections are explored via the lens of transformative learning theory. The themes generated from the data relate either to the nature of learning as experienced by the participants or to the need for unlearning prior meaning perspectives on race.

Keywords: experiential learning, leadership, personal transformation, transformative learning

\section{INTRODUCTION}

How do leaders become aware of the baggage they carry and how this may constrain their leadership and lives? Understanding this process is part of the vitally important transformative learning needed for leading change in the context of a divided South Africa. "All of a sudden you are free and your baggage is gone. It has made me a light traveller", are the reflections of a participant of the Nexus Leadership Programme. These reflections highlight the sudden realisation of shackles being loosened and, in becoming a "light" traveller, the participant is freed from carrying burdens imposed on her by apartheid's boundary-defined past in South 
Africa.

Globally, leadership training at institutions of higher learning typically focuses on a curriculum based on the theories and practices of leadership through taught content. In South Africa this, too, is the case, but at a few higher education institutions (HEIs) and business schools there is a focus on the person in leadership and their context. In addition, there have been moves in South Africa to professionalise education management and leadership since 1996 (Van der Westhuizen and Van Vuuren 2007) and a variety of programmes have been formulated to help with leadership development in educational settings (Collett and Green 2017; Naicker and Mestry 2016; Van der Westhuizen and Van Vuuren 2007). These programmes, too, foreground theories and models of leadership (see, for instance, Albertyn and Frick 2016, 18). However, in a call to shift to innovative ways of teaching leadership skills and sharing of knowledge, Albertyn and Frick $(2016,12)$ highlight the importance of context and collaboration in the process of developing leadership. The Nexus Leadership Programme (hereafter also referred to as Nexus), situated in the Gordon Institute of Business Science at the University of Pretoria, is such a case which exemplifies the importance of context by helping leaders recognise and deal with their baggage in collaborative dialogue with others, in preparing them to surface and revise unexamined perspectives. In such a context, how people make sense of the world and how they act in the world in general and as leaders is significantly shaped by the perspectives developed in the past. Learning about leadership thus has to be accompanied by deep and critical reflection on one's perspectives and how these perspectives have been shaped by a past of fracture and hurt.

For Walker (2017), learning about self is more important than learning content from a curriculum. Education is "fundamentally about self-awareness, being present, and radically accepting the present moment, including our emotional state; it allows us to harness the power of the affective to help us better able to learn" (Walker 2017, 370). The role of emotions and relationships becomes crucial in such learning. There is insufficient scholarship of leadership learning of this type and in contexts of deep and painful division.

Burns $(2015,261)$, writing on teaching and learning about sustainability, notes that to bring about the necessary changes in how people understand issues of sustainability and how to respond to this new understanding requires a "move beyond traditional styles of education in which individuality, intellectual rigor, rationality, and transfer of knowledge are privileged in the educational process". In a similar fashion, Fotaki and Prasad (2015) concur with Burns's view about the foregrounding of individuality, rationality and taught content, particularly within business schools. They go further to say that it is the very content taught in business schools that "is weak in acknowledging pre-existing social differences" and which gives rise to 
a lack of "sense of social embeddedness and connectedness with the range of individuals and communities who are affected by business activities" (Fotaki and Prasad 2015, 558).

Nexus stands out for its teaching approach which focuses on both social embeddedness and connectedness, particularly in response to South Africa's developing democracy, which is still dealing with past differences defined predominantly by race and class. As the recent Covid19 pandemic has highlighted across the globe, these differences continue to impact the poorest and marginalised in all societies.

\section{THE CONTEXT: THE NEXUS LEADERSHIP PROGRAMME}

Despite South African government-led initiatives (Republic of South Africa 2003, 2014) to redress disparities in employment and eliminate demographic distortions, a comparison of Black African and Whites in the private sector in management positions highlights these disparities, particularly in top leadership positions. Seventy-eight per cent of economically active participants (EAP) are Black of which 10,7 per cent are in top management, and 15 per cent in senior management. By contrast, 9,5 per cent of EAP are White with 72 per cent occupying top management positions and 63 per cent in senior management (Republic of South Africa 2016/2017).

Vassilopoulou et al. $(2013,19)$ go further to note that the White minority acts to "entrench and protect their institutional power in corporate South Africa". Although Black managers and leaders are indeed appointed into leadership positions within organisations, lack of skills and experience are further compromised through actions such as undermining decisions made by these leaders, reinforcing imposter syndrome, co-opted silence, and a helplessness to address the status quo: what Vassilopoulou et al. (2013) call "empowered powerlessness". Bosch et al. $(2015,421)$ highlight "the need to undo the deep racial and gender inequalities that were entrenched in societies and in organizations during apartheid."

Although the South African government has measures in place to deal with discrimination "in reality the workplace can be a contested space marked by resistance, non-compliance, exclusion, prejudice and racism" (Spooner 2018, 7).

Nexus is an innovative programme which represents an alternative paradigm of a leadership programme at an institution of higher learning. The programme prioritises learning about oneself and one's beliefs over a taught formal body of knowledge. A further distinguishing feature of the programme is its deeply experiential and dialogical pedagogy. Nexus was specifically designed to equip leaders for a post-apartheid South Africa. Apartheid, which ended formally in 1994 with the establishment of a politically democratic South Africa, deliberately separated people by race and space. In post-apartheid South Africa these 
separations continue socially and economically, with high levels of mistrust evident between groups of people, largely based on race or class. Learners at public schools, particularly in rural areas, continue to be largely drawn from one population group, given that spatial divides have not changed significantly. Many students entering HEIs may experience interacting with those from other race groups and cultures for the first time.

Perspectives based on past experiences continue to be established and perpetuated in today's South Africa. For all leaders having to navigate a transforming society, it becomes imperative that these leaders are equipped to lead well (Naicker and Mestry 2016; Van der Westhuizen and Van Vuuren 2007), but furthermore to lead a fractured society well. When prompted to reflect on their learning during their year on the programme, many participants responded by contrasting this learning about leadership with a more formal understanding of learning gained through their prior university studies. Race and identity are predominant concerns tackled by many participants during Nexus. Emerging themes include how changing perspectives impact the lives of some participants, leading them to explore new ways of active citizenship or connection to their fellow humans.

Participants of the Nexus Leadership Programme are exposed to the larger South African societal context through an experiential learning approach. The 8-month programme includes learning journeys, focused dialogue sessions in working groups, a weekend retreat, projects that integrate learning with applications of dialogic principles, and seminars with influential citizens and leading thinkers. The features of the programme are summarised in Table 1.

Table 1: Nexus Learning Approach (Nexus 2017)

\begin{tabular}{|c|c|c|c|}
\hline Features of Programme & What this is & Who & Why \\
\hline Learning journeys & Day-long field trips & $\begin{array}{l}\text { Communities, } \\
\text { government and } \\
\text { business initiatives and } \\
\text { historical sites }\end{array}$ & $\begin{array}{l}\text { To become aware of } \\
\text { assumptions and biases in } \\
\text { preparation for subsequent } \\
\text { dialogue }\end{array}$ \\
\hline Guest speakers & $\begin{array}{l}\text { Personal and direct } \\
\text { engagement with leaders } \\
\text { during learning journeys }\end{array}$ & $\begin{array}{l}\text { State, business and } \\
\text { social sector leaders }\end{array}$ & $\begin{array}{l}\text { Gain personal insights from } \\
\text { leaders who have practical } \\
\text { experience of issues under } \\
\text { discussion. }\end{array}$ \\
\hline Dialogue & $\begin{array}{l}\text { Monthly small group } \\
\text { meetings, called Working } \\
\text { Groups }\end{array}$ & $\begin{array}{l}\text { Nexus participants and, } \\
\text { during early phase of } \\
\text { programme, Dialogue } \\
\text { Coaches }\end{array}$ & $\begin{array}{l}\text { Dialogue in order to gain } \\
\text { new insights and ideas, and } \\
\text { to deepen understanding. }\end{array}$ \\
\hline Retreat & $\begin{array}{l}\text { Day and a half off-campus } \\
\text { retreat }\end{array}$ & Nexus participants & $\begin{array}{l}\text { Develop greater self- } \\
\text { awareness and deepen } \\
\text { understanding of authenticity }\end{array}$ \\
\hline $\begin{array}{l}\text { Community Learning } \\
\text { Project }\end{array}$ & $\begin{array}{l}\text { Day long interaction with a } \\
\text { community not normally } \\
\text { encountered }\end{array}$ & Communities & $\begin{array}{l}\text { Applying learning from } \\
\text { Nexus in a community } \\
\text { context }\end{array}$ \\
\hline Assessment & Tasks or assignments & Nexus participants & $\begin{array}{l}\text { Practical application of } \\
\text { learning and reflection on } \\
\text { experience }\end{array}$ \\
\hline Weekly provocations & $\begin{array}{l}\text { Emails that encourage on- } \\
\text { going reflections and }\end{array}$ & Programme Management & $\begin{array}{l}\text { Reflections on issues and } \\
\text { themes raised during }\end{array}$ \\
\hline
\end{tabular}




\begin{tabular}{|l|l|l|l|}
\hline Features of Programme & What this is & Who & Why \\
\hline & application of learning & & programme \\
\hline
\end{tabular}

Pedagogically, there is an emphasis on storytelling, the practices of dialogue (listening, suspending judgement, voicing and respecting), and reflection through assignments, projects and dialogue in working groups. In our discussion of the themes, we will reflect on the pedagogy but here it is worth noting that the practice of dialogue, as understood in the milieu of Nexus is distinct from a common sense understanding of dialogue. Dialogue, from the perspective of Nexus, is understood to happen only when all participants consciously enter into dialogue, most often during their working group interactions, and when all participants have an understanding of the principles of dialogue.

A hallmark of the programme is its focus on diversity. Diversity matters because as DiTomaso, Post and Park-Yancy $(2007,475)$ note "individuals give social significance to the categories or groups they associate with certain people. ... diversity implies group-based inequality that is relatively stable but nevertheless subject to potential challenge." In the Nexus programme, participants are able to explore how and why there are relationships of power associated with certain groups of people.

Race is a significant marker, given that apartheid classifications of race continue to shape identities and relationships amongst participants. As noted by Gibson (2015), it is common practice in South Africa to use four race categories, that of Black (African), Coloured (Mixed), Indian (Asian) and White (European), and this article uses these categories too. Race and gender too have been central in either privileging or subjugating groups of people, and often lie at the heart of debates of what it means to be South African in the new democracy.

This article discusses findings from a study of the UP GIBS Nexus Leadership Programme which reveal profound learning at a personal level and an undoing of meaning perspectives, as reflected in the quotation in the opening paragraph. Data gathered through interviews with the programme managers, focus group discussions with past participants and members of a working group (defined in the next section) point to the difficulties and discomfort participants experienced during the Nexus programme when forced to reflect on their assumptions. As part of ethical teaching practice, the programme management team has measures in place for safety and support for participants. Four key themes are discussed, these being taking risks, critical reflection and disorientations, learning through relationships, and changing perspectives of race. Metaphors of journey and space being redefined abound in the data.

The reflections and learning of Nexus participants are explored via the lens of transformative learning theory (Mezirow 1981, 1990, 1998, 2000a, 2000b). "Transformative 
Theory [sic] deals with how individuals may be empowered to learn to free themselves from unexamined ways of thinking that impede effective judgment and action" (Mezirow 1998, 72) and the quote in the opening paragraph, "all of a sudden you are free and your baggage is gone" speaks powerfully to this.

\section{THEORETICAL PERSPECTIVE: TRANSFORMATIVE LEARNING THEORY}

The central concept in transformative learning theory is that adults learn by transforming their meaning perspectives. In this study one powerfully changed meaning perspective reported by the Nexus participants resulted in a revision of relationships with people to become more accepting of those of another gender, race, culture, class and sexual identity. Meaning perspectives are psychological and cultural assumptions which frame the way we think, feel and act. An inability to transform perspectives constrains the way we live and relate to others. Perspective transformation, a "central function of adult education" (Mezirow 1981, 65) is understood "as a quest for meaning by which to better understand ourselves and to anticipate events" and "the process of becoming critically aware of how and why the psychocultural assumptions has [sic] come to constrain the way in which we perceive our world, of reconstituting that structure in a way that allows us to be more inclusive and discriminating in our integration of experience and to act on these new understandings" (Mezirow 1985, 22).

Mezirow identified a type of learning that emerges when people are confronted by certain dilemmas or life crises, a matter that cannot be resolved "by simply learning more about them or learning how to cope with them more effectively" (Mezirow 1978, 101). Later, he (Mezirow 1981, 65) was to term this a disorienting dilemma: "a sudden insight into the very structure of cultural and psychological assumptions which has limited or distorted one's understanding of self and relationships". Walker (2017, 370), citing Palmer, offers the view "that authentic, deep, and transformational learning necessitates a journey of self-discovery. This is how we learn from 'disorienting dilemmas' (Mezirow 1991) and are able to 'learn from the experiences we learn from'." In the findings section we discuss how participants referred to their disorienting dilemmas as disorientation or disruption or disconnection.

Mezirow considers the most significant distinguishing characteristic of adult learning as the ability to embark on critical self-reflection. When we become critically reflective, we challenge "the established definition of a problem being addressed ... [through] reassessing the way we have posed problems and reassessing our own orientation to perceiving, knowing, believing, feeling and acting" (Mezirow 1990, 12-13). We show that while adults indeed have the capacity to critically reflect, this is not always habitually done. Some participants felt that 
they were "forced to" self-reflect, one of the findings of this study.

The socio-historical context for participants of Nexus is that of a country in transition the new democracy is 25 years old, but deeply held beliefs and half-truths instilled through apartheid mean that some people continue to be caught in their own history and to relive it. Nexus provides opportunities to confront such half-truths and to self-reflect on why these truths are perpetuated.

Mezirow $(1985,19)$ drew on the work of Habermas in defining ideal conditions for discourse. He states:

"Ideally, participants in a discourse have full information about the matter at issue, they are able to reason argumentatively, they can reflect critically about assumptions and premise, and they have sufficient self-knowledge to assure that participation in discourse is free from selfdeception."

Nexus uses self-facilitated dialogue sessions called working groups where the participants are free to collaboratively engage in validating discourse. Again, in the findings section reference made by a Nexus participant highlights how dialogue allows for critical self-reflection and a process of freeing oneself from self-deception.

While now a major theory in adult education, transformative learning theory has emerged from robust critique and continuing development in response to critique. A key aspect of this was that learning in the early version of the theory was seen as largely cognitive and rational with little emphasis on the role of the affective domain and the importance of relationships in learning (Dirkx 2001; Taylor 2001). In this article we show that the development of trust in relationships helps to foster transformative learning.

\section{THE RESEARCH PROCESS: INVITING REFLECTIONS ON LEARNING ON NEXUS}

While researching learning in Nexus, data were collected from 20 participants during three focus group discussions and interactions during one working group session, each session lasting just over two hours. Semi-structured interviews were also conducted with four programme managers as well as in-depth interviews with six programme participants. Pseudonyms for research participants are used when reporting the data. As stated in the introduction, perspective transformation on race emerged as one of the themes, and so the race, as well as the gender, of the research participants are reported in Table 2. Focus group discussions comprised those who had participated in previous years' Nexus programmes (hereafter noted as "past participants") who were asked questions that prompted them to reflect on how they understood their learning 
in Nexus; whereas during the working group the session was self-facilitated and directed by the group-members themselves. The working group session that was observed took place on the last day of the programme, and was at the invitation of group members.

All research participants signed an informed consent document, and all were advised of their right to withdraw from the research without prejudice. To ensure safe and ethical research, during the focus groups, working group and interviews, when I became aware of discomfort or distress, I offered to stop or to withdraw. In no instances was that invitation accepted. All sessions were audio-recorded and transcribed. The resulting transcripts comprise approximately 73000 words. The transcripts were coded inductively and then categorised into several themes.

The data generated four main themes related to learning. Some reflect the pedagogy of Nexus and others link strongly to transformative learning theory. The themes also relate either to the nature of learning as experienced by the participants, namely being forced to engage, learning through disorientations and critical reflection, and learning through relationships, whilst the fourth theme relates to the need for unlearning through changing perspectives on race.

Table 2: Participants by data gathering event, race and gender (pseudonyms used)

\begin{tabular}{|l|c|c|c|}
\hline \multicolumn{1}{|c|}{ Name } & $\begin{array}{c}\text { Focus Group (FG)/ } \\
\text { Working Group (WG) }\end{array}$ & Race & Gender \\
\hline Ajman & FG & Black & Male \\
\hline Avinash & FG & White & Male \\
\hline Boss & WG & Black & Male \\
\hline Buyani & FG & Black & Male \\
\hline Henry & WG & White & Female \\
\hline Jann & WG & White & Male \\
\hline Joe & FG & White & Female \\
\hline Laurie & WG & Coloured & Female \\
\hline Leazal & FG & Coloured & Female \\
\hline Lerushka & FG & Indian & Female \\
\hline Lexie & FG & White & Female \\
\hline Luleka & FG & Black & Male \\
\hline Mandla & FG & Black & Female \\
\hline Ngao & WG & White & Male \\
\hline Niel & WG & White & Male \\
\hline Pierre & FG & Indian & Male \\
\hline Pravin & WG & Coloured & Female \\
\hline Sammy-Jane & FG & Black & Male \\
\hline Tebang & WG & Black & Male \\
\hline Tebatso & FG & & \\
\hline & & & \\
\hline
\end{tabular}


In this next section we deal with three themes as they relate to transformative learning theory. While these themes have been reported using the descriptions participants provided, they each relate to key concepts in transformative learning theory.

\section{THE FINDINGS: DISCOMFORT AND COMFORT}

Mezirow described ten "phases of meaning becoming clarified" (2000a, 22), and the experience of learning in the Nexus Leadership Programme highlights three key concepts from these phases in transformative learning theory. Participants reported feeling "forced to ...", particularly with regard to self-reflection and what Mezirow holds is a critical assessment of assumptions; that they experienced disconnections between their understanding of the world and what they were experiencing in Nexus, a disorienting dilemma as described by Mezirow; and that learning was enabled through the forming of new relationships (another phase of meaning-making), particularly with people from other races.

\section{Forced to ...}

One of the most common phrases used by participants is "Nexus forces you to ...". Six participants made statements like this. What they appear to be raising is the provocative and disruptive nature of Nexus pedagogy.

There are three different ways in which participants appear to have felt this provocation. For some like Leazal and Joe (an immigrant), it was about being forced to reflect on something that they prefer not to reflect on. One sees this in the following two statements:

"That forced reflection was a bit annoying at first. ... It is not something that I do in my everyday life, I don't meditate or sit and think about what maybe happened in the day or sort-of plan ... sit and meditate about it, and you are almost forced to do that, there is a discomfort and fidgety feeling" (Leazal).

"I have still, but had even more so, a huge prejudice towards Afrikaners as well. I don't know if it just developed since I've been here and the interactions that I've had with Afrikaners has [sic] just been really problematic around race. Nexus actually forced me to deal with it, at least start to deal with it. I am still dealing with it" (Joe).

For others like Pierre and Laurie, Nexus compelled them to have difficult conversations. We see this when Pierre says, "They kind of put you a bit into a pressure cooker and say, 'Okay, now talk about it'. They kind of forced you to talk about some of the tougher topics."

And Laurie says, "I am going to miss this forcing us to get in a room, forcing us to talk even when we didn't want to and always leaving with a lesson".

Another important aspect of forced realisation has to do with being aware of, and critically 
scrutinizing, one's premises and perspectives (Mezirow 1985). Tebang conveys this new consciousness best when he says:

"You can never leave behind what your background is but it doesn't mean [you] must allow it to create that tunnel vision. I think this forces you to see beyond that tunnel vision which I don't think any of us have perfected by any stretch of the imagination, but it is something that is consciously there now."

The language of being forced or compelled is worthy of closer scrutiny. Nexus is a voluntary programme in which respectful and open sharing in a non-hierarchical and non-coercive manner is encouraged. The ethos of the programme is thus the antithesis of regulated and directed learning. So why is there such regular reference to being forced? We believe that this language reveals the levels of conscious and subconscious resistance that South Africans have developed to engaging with a fractured and painful past. In the normal routine of life, one is able to avoid having to reflect and discuss certain topics such as racial and cultural differences and values. Nexus, however, invites and provokes engagement with these topics.

\section{Disorientations, disruptions, disconnections}

"There is momentary disconnect between your idea of the world and this new reality that gets created. There is a shift. Then you need to reconcile that shift somehow" (Pierre).

Pierre's comment ties in with Mezirow's explanation of learning taking place through revised meaning perspectives. Mezirow's (1981) disorienting dilemma is described by Pierre as a "momentary disconnect". Furthermore, his reconciling of that shift could be explained from the theory that some disorienting dilemmas trigger reflections. If these reflections cause the person to reflect on premises or paradigms that guide their meaning making and to change these, then transformative learning is said to have taken place. Pierre's use of the phrase "this new reality ... gets created" could refer to his revised meaning perspectives.

For many of the participants there is some form of disruption in how they make sense of their world as a result of their involvement in Nexus. These disruptions appear to lie on a spectrum from rational and cognitive responses through to experiencing turmoil as existing meaning perspectives are revised. Study participants also reported on how these disruptions to their understanding had changed the way in which they thought about what was truthful and real.

Words and phrases used when reflecting on their frames of reference, or as Kegan (2000, 52) notes is "a way of knowing", include recognition of stereotypes (Buyani, Boss, Joe, Lexi), of being stereotyped (Avinash, Pierre), that one's views are informed by those of one's own 
parents or grandparents (Avinash), and that there is a need for working things out for themselves (Pierre). At the other end of the spectrum expressions such as challenging (Niel, Pierre, Sammy, Lerushka), shaken (Pierre), cognitive dissonance (Pierre), struggle (Sammy), not enjoyed (Tebang, Niel ), hard discussions (Laurie, Tebang, Tebatso), heated discussions (Pierre), discomfort (Leazal), being thrown into (Mandla), questioning one's beliefs and values (Pierre, Jann), moving out of comfort zones (Henry, Tebang), tested in the crucible, in the furnace (Pierre) convey a sense of difficulty in revising their understanding.

The following quotes are indicative of how experiences and dialogues in Nexus provoked "a critical assessment of assumptions" (Mezirow 2000a, 22) through deeper thinking about the participants' previous understanding and how their meaning had been constructed: "so much to analyse and realise and understand" (Jann); "left thinking there is a lot we don't know" (Avinash); "she also had to think hard and he had to think hard. Everybody thought" (Pierre). These quotes also indicate that this process of thinking deeper about what was previously held to be true continues beyond the experience and dialogue.

Participants reflected that their learning included emotions that Mezirow (2000a, 22) expressed as "self-examination with feelings of fear, anger, guilt, or shame". Some of the turmoil experienced when meaning perspectives are disturbed include observations that: "[I'm] struggling with something I've never really let come forth" (Ngao); "I may not have enjoyed some of it but it was good for my learning at that point in time" (Tebang); "It is hard 'adulting"" (Jann); "it [Nexus] took you and shakes you a little bit and now go. ... your leadership traits, skills, beliefs are being tested in the furnace, in the crucible" (Pierre). Niel says:

"There are some things I didn't particularly like, but you had to get through it [the experiential learning day] and learn from it and then move forward. I know there were a lot of people who complained about some of the days, but I think we all had to learn something."

This supports the notion that there are moments of great difficulty when grappling with making sense of what has been experienced.

One of the experiential learning days in particular (see Table 1 for a brief description of experiential learning days) elicits powerful emotions amongst Nexus participants leading to many reports of resultant disorienting dilemmas. The experiential learning day focuses on South Africa's past and is embedded in the stories of the days of apartheid, and also what gave rise to the policy of separation amongst races. The final visit of this experiential learning day takes place at Vlakplaas. Under the apartheid government, Vlakplaas operated as the home of the counter-insurgency unit of the South African Police. Political opponents of the apartheid government were tortured, were executed by death squads that made bodies disappear in their 
own unique ways (De Waal 2013), or were turned into agents for the government. Vlakplaas serves as a stark reminder of the atrocities carried out by the apartheid government on those opposed to the state. Experiential learning days on Nexus trigger deep reflection and dialogue. Pierre says:

"It [Vlakplaas] is a funny place. The hair on the end of my neck still [stands up] ... when I talk about Vlakplaas. Now there are funny things that happened at that place. There's a funny vibe there. Then we came back and they say 'Just talk'. Jeez and guys just talk."

That space is created for participants to find "new ways for talking" (Wiessner and Mezirow 2000, 336) can lead to transformative learning. The importance of being able to listen and being listened to is described by Mezirow (Wiessner and Mezirow 2000, 337) as "empathic listening in discourse."

Hersted (2017) describes a process where role-play was used to enhance dialogic and relational skills within an organisational setting. She notes that "the role-playing challenges were loaded with tensions, reflecting conflict and alienation within the organization itself. I viewed these role-playing challenges in terms of what Mezirow (1994) calls disorienting dilemmas" (Hersted 2017, 143). Citing Mezirow (1991), she states that "the educator who wishes to facilitate transformative learning provides different meaning perspectives" (Hersted 2017, 144). This stands in contrast to the experience on Nexus where participants provide different meaning perspectives on their own and without the educator.

As meaning perspectives are disrupted, there is a sense that nothing stays the same afterwards. Two such reflections come from Jann and Pierre. Jann says, "You can't un-see what you have seen", while Pierre explains, "they throw you through that wall. Then you get to see ... once you crash through it you are seeing something else and you are not the same thereafter". In addition, new spaces appear to open up for participants, as revealed in the following statements: "I don't believe that I need to have it all figured out now but I am on a journey and that is okay" (Laurie); "I think I have learnt to take that emotion and be comfortable with it. ... kind of opened my mind to thinking we are different and it is fine" (Tebang); and, "you actually see a different side and you appreciate that more. It changes the way you think about things" (Avinash).

We see again in the preceding paragraph a metaphor of blockage as expressed by the wall. Nexus seems to provide a way of getting through these blockages by helping people to reflect on how they have come to think about their context. Nexus provides entry and access points across boundaries which result in changes in identity. Pierre's remark that "you are not the same thereafter" is about learning to be different. 


\section{Relationships and learning}

"We sat and broke bread and talked" (Buyani).

Transformative learning has been shown to depend on the "need for support, trust, friendship and intimacy" (Taylor 2007, 187), and our attention now turns to the nature of these relationships.

Nexus participants report on how what they have learnt during Nexus has impacted how they interact with colleagues at work, and in their personal lives, and that they have found new opportunities for learning about the world in which they live. Some participants link learning about practices of dialogue to having an impact on their relationships, others report that learning how to form relationships based on trust has helped them revise their meaning perspectives.

Five participants reported on how the various components of dialogue had improved relationships with members of their families. Laurie says: "[using] the practices of dialogue in an authentic way ... will strengthen our relationships with our family and how we deal with things and problems", and Henry's observation is that:

"I made a decision at home - I will make a decision to completely switch off from my job because I found that I was listening or engaging after hours with something at work and you bite your kids' head off - so listening to [my family members] $-100 \%$ focused on that and not 50/50. So, [from] a personal perspective that has helped me massively in life."

For Avinash, he "noticed that I was talking to, for example, my parents differently, where I sort of opened up conversations that I had never had with them and I could be more confident in the way I spoke about it [a specific topic]". Tebang's insight was that being part of Nexus moved him "further into your personal space and in my personal relationships as well. It is about having those hard conversations with people sometimes that you need to have". These participants have found new ways of engaging with their family members, to the point of feeling that things that had previously been unsaid could now be discussed with confidence and courage.

Other participants reported that their learning came through new relationships that they had established with fellow Nexus participants, and others. In fact, being able to form strong relationships based on the principles of dialogue had opened new opportunities for many of the participants. Boss said that "this Nexus programme taught me the meaning of valuing relationships and I do now", and Niel was able to look beyond differences in people and to "listen to people and understand cultures better and understand where people are coming from and not just think that my world is the best world and the only world that exists. I think that was a key message for me". It is through forming relationships that are more inclusive of others' 
points of views that new learning becomes possible.

During the closing session of the working groups, Boss said that although it was not easy to travel the long distance between his home town and the Johannesburg campus to attend Nexus events, and that he had to sacrifice time spent with his own family, "being part of the group I learned a lot. I felt home from home".

Jann's reflection about her learning to the group was:

"I don't think my experience would be like this if it wasn't for all of you in the room and all of you bringing your heart and your honesty and your courage to the table as well, learning from one another."

It is noticeable that Jann does not point to learning though the knowledge and cognition of the group members. She highlights the features present that helped to build trust amongst the group, and points to the role that affect has had on her learning. Jann's reflections above support Dirkx's $(2001,65)$ argument that "as we look at and come to understand our sense-making practices in daily life and the ways emotions constitute that practice, we reveal ourselves more fully to ourselves and to others". Jann's experience of coming to know herself more fully was possible because of the "heart", courage and honesty of the others in her working group.

\section{DISCUSSION: CHANGED PERSPECTIVES AND RELATIONSHIPS}

Learning in Nexus meant that one outcome is that participants were able to revise their relationships with those from other cultures and races. In a context of post-apartheid South Africa this is a significant shift in one's meaning perspective: under apartheid forming any kind of relationship with a person from another race was not only illegal and forbidden, but also deemed unthinkable. Taylor $(2000,306)$ notes that "relational knowing of transformative learning refers to the role that relationship with others plays in the transformative process" (emphasis added). Relational ways of knowing is a recent addition to transformative learning theory, and in the case of the Nexus programme it is pertinent that not only does relationship with others play a role in learning, but the very nature of the relationships is transformed.

\section{Changing perspectives on race}

"There has always been this friction between Black and White because of [the fact that] we don't engage, we don't talk" (Boss).

Racism continues to threaten the nation building of South Africa, and indeed threatens its very democracy (Soudien et al. 2008). South Africa's fractured past continues to adversely impact relationships between people of different races, cultures, faiths, religion and 
nationalities. There is currently a draft national action plan (Department of Justice and Constitutional Development 2016) intended to deal with various forms of intolerance. Whilst socially there may be some sense of control over how people choose to interact with "others", often in the workplace there is limited choice. This is especially significant for those who have to exercise leadership at work, whose role now includes leading a fragile and fractured society and workplace. It is in this context that Nexus provides a space and place where participants from diverse cultures, backgrounds and work sectors can grapple with racial biases and other forms of intolerance. Such experiential learning for educational leaders can be particularly valuable for allowing them to use their institutions to further such learning to the wider society.

During Nexus, participants report that for the first time they are able to have conversations that they have never been able to access before, and to get to know those from other races and cultures. Buyani was part of the first Nexus group in 2002 at a time when South Africa's new democracy was still in its first decade. Reflecting on the conversation during the focus group session he said:

"There is a time and space conversation that is here [in the focus group] which is different for different people. Maybe in my case everybody wanted to talk to everybody. We [had] just met White people. They didn't exist [before]. We were tolerant."

Here Buyani is thinking back to a time early in democracy when he felt a tolerance towards a more inclusive society. The recent discourse in South Africa, played out through social media, is one of mistrust especially along racial lines.

Buyani, a Black man, recalls that under apartheid people from separate races were kept apart to the extent that for him, White people had not previously existed in his world. Avinash explains that "in the apartheid country you had [the] White community, [the] Black community ... all living separately. This programme [Nexus] comes and takes you and throws you across each one, breaking down all those walls". This is a powerful metaphor about how these previous and continuing separations have a physical element to them: it is as if walls continue to divide society and keep people separated.

In a study of various undergraduate leadership programmes, Cohen et al. (2013) found three practices in the development of leaders, namely "discerning differences and bringing those differences into dialogue; revising their sense of themselves and becoming more serious students; and revising relationships and creating community" (Cohen et al. 2013, 3-4). In South Africa, it is these very differences between people that Buyani and Avinash highlight, where others are only ever seen through because of their differences. Nexus allows for dialogue to show that these differences can be broken down in order to revise relationships and create 
community.

Some revisions of meaning perspectives come about through dialogic learning. Boss, a Black man, states:

\begin{abstract}
"In terms of this thing of [the] Black and White issue which I think is the thorny one in the country, we can only realise [what the issues really mean] if only we engage in this debate. Talk about it. There has always been this friction between Black and White because of [the fact that] we don't engage, we don't talk."
\end{abstract}

Here Boss reflects on the lack of space to engage and enter into dialogue with people of a different race. This lack of opportunity to dialogue and interact has in the past led him to not understand the meaning of certain communications with White people, in fact it caused him to understand these as insults. He says:

"I personally am grateful that Nexus assisted me for [to develop] tolerance on [of] a different skin of [from] mine. I promise you. ... some people have dry jokes and sometimes so-called 'White jokes' - they can be dry - but you laugh about them because you understand what you mean. It has taken me, a darkie, who takes some time to understand."

It is in this new understanding that we see that Boss's meaning perspectives have been revised to the extent that he now understands the subtlety of the dry jokes, and he has broken down the sense of the joke being a slur against him.

For Pierre, a White man, the revised meaning perspective came through realising that his actions could lead to people from other races feeling excluded. He tells the following story:

“... again it was a race issue. It was a race discussion and the one person said, 'White people will never like us being a Black guy'. I said, 'Why do you say that?' He said, 'No, they just don't like us. If you get into a lift [elevator] they will never greet you.' I said, 'But we don't greet other Whites either'. We had this whole thing, there is a big cultural thing where people think you are rude and we just think, that started to change. I know [now] if I get into a lift with three Black guys I will say, 'How's it, all right gents?' If I get into a lift with three White guys I just stand there and look at the numbers and then get out."

Pierre's awareness of his perhaps previously unconscious habit of not greeting Black people has now resulted in him acting differently. He now acknowledges the presence of Black people but interestingly does not extend this changed practice to when he is with his own racial group.

Dave is a long-standing member of the team that facilitates learning on Nexus, as well as another leadership programme, Spirit of Youth, for Grade 11 and 12 learners from a selection of diverse schools in Gauteng. He notes that part of the systemic issues around race begin during 
the school years. He says:

"Nexus is a catalyst for change in the sense that you don't have to change your career, your lifestyle, but the way you look at your life and the way you look at this country. Because we know that how we look at this country has been informed by our past; now to undo that - even our schooling system is not able to do that. You see it in the kids that come to the Spirit of Youth that in fact it is being reinforced [in the schools] - and it is only when they go through the programme, which is designed according to Nexus [principles], the way these kids come out and are like 'Wow, I didn't know, realise that this is what is going on!"'

Dave is in part highlighting a consequence of the lack of diversity in schools. The ability to live and work in old comfort zones means that people are not challenged in the way Nexus participants report. The idea of being "forced to" in Nexus is perhaps because little else forces people to engage.

\section{CONCLUSION: ENABLING LEADERS TO BE CHANGE AGENTS}

The Nexus leadership programme can be seen to shape participants in terms of how they make sense of the country and their lives. Perspectives are transformed, relationships and trust across previous divisions are built, and new identities formed. Nexus not only guides their leadership at work but also in their domestic and community spaces. For those who participate in the Nexus leadership programme, the focus lies on learning more deeply about self rather than learning more about the concept of leadership. In this way, Walker's $(2017,370)$ view that the motivation for education should be on developing self-awareness and "radically accepting the present moment, including our emotional state" is seen as the lived-experience of learning on Nexus, as reported in the data.

Such powerful experiential learning for leaders of schools, colleges and universities in South Africa could bolster a conviction for them to use their institutions as spaces for such critical learning on a wider scale, with a concomitant multiplier effect. When more leaders experience such transformation, they could become powerful multipliers of such change. The report by Soudien et al. (2008) highlights the need for much work in this area but few, if any, programmes exist to enable leaders to become these powerful change agents. Nexus provides not only insights for what the focus of such a programme should be in terms of its content, but also for the pedagogy it uses.

The data report on the courage and willingness to engage with discomfort expressed by the participants, but also that such self-work leads to a freeing of invisible and tenacious constraints. It is noteworthy that dealing with hurts and fears is facilitated by the members of the group themselves. These participants are exposed to facilitation training, but it is the 
members of the group who take collective responsibility for their learning. It appears that this programme, which encourages its participants to take responsibility for their learning represents a truly innovative and transformative approach to learning about leadership.

\section{Declaration of conflicting interests}

The author(s) declared no potential conflicts of interest with respect to the research, authorship, and/or publication of this article.

\section{Funding}

The first author received partial funding from the university towards doctoral studies.

\section{REFERENCES}

Albertyn, R. and L. Frick. 2016. A collaborative higher education initiative for leadership development: Lessons for knowledge sharing. South African Journal of Higher Education 30(5): 11-27.

Bosch, A., S. M. Nkomo, N. M. H. Carrim, R. Haq, J. Syed and F. Ali. 2015. Practices of organizing and managing diversity in emerging countries. In The Oxford Handbook of Diversity in Organizations, ed. I. B. R. Bendl, E. Henttonen and A. J. Mills. Oxford: Oxford University Press.

Burns, H. L. 2015. Transformative sustainability pedagogy: Learning from ecological systems and indigenous wisdom. Journal of Transformative Education 13(3): 259-276.

Cohen, J., A. Cook-Sather, A. Lesnick, Z. Alter, R. Awkward, F. Decius, L. Hummer, S. Guerrier, M. Larson and L. Mengesha. 2013. Students as leaders and learners: Towards self-authorship and social change on a college campus. Innovations in Education and Teaching International 50(1): 3-13. doi:10.1080/14703297.2012.746511.

Collett, K. and L. Green. 2017. "Walking the talk": The influence of an introduction to cognitive education on school leaders. South African Journal of Education 37(3): 1-9.

Department of Justice and Constitutional Development. 2016. National Action Plan to combat racism, racial discrimination, xenophobia and related intolerance (2016-2021) - Draft for public consultation. http://www.justice.gov.za/docs/other-docs/nap.html (Accessed 28 January 2019).

De Waal, M. 2013. Jacques Pauw on Vlakplaas' apartheid assassin, Dirk Coetzee. Daily Maverick. http://www.dailymaverick.co.za/article/2013-03-08-jacques-pauw-on-vlakplaas-apartheidassassin-dirk-coetzee/ (Accessed 29 July 2016).

Dirkx, J. M. 2001. The power of feelings: Emotion, imagination, and the construction of meaning in adult learning. New Directions for Adult and Continuing Education 2001(89): 63-72.

DiTomaso, N., C. Post and R. Parks-Yancy. 2007. "Workforce diversity and inequality: Power, status, and numbers." Annual Review of Sociology 33: 473-501.

Fotaki, M. and A. Prasad. 2015. Questioning neoliberal capitalism and economic inequality in business schools. Academy of Management Learning \& Education 14(4): 556-575.

Gibson, J. L. 2015. Apartheid's long shadow: How racial divides distort South Africa's democracy. Foreign Affairs 94(2): 41-48.

Hersted, L. 2017. Reflective role-playing in the development of dialogic skill. Journal of Transformative Education 14(4): 137-155.

Kegan, R. 2000. What "form" transforms. A constructive-developmental approach to transformative learning. J. Mezirow and Associates. Learning as transformation. Critical perspectives on a theory in progress, 35-69. San Francisco: Jossey-Bass Inc.

Mezirow, J. 1978. Perspective transformation. Adult Education Quarterly 28(2): 100-110. 
Mezirow, J. 1981. A critical theory of adult learning and education. Experience and learning: Reflection at work. Adults learning in the workplace: Part A. Victoria, Australia: Deakin University.

Mezirow, J. 1985. A critical theory of self-directed learning. New Directions for Adult and Continuing Education 1985(25): 17-30.

Mezirow, J. 1990. How critical reflection triggers transformative learning. In Fostering critical reflection in adulthood, ed. J. Mezirow, 1-20. San Francisco: Jossey-Bass Publishers.

Mezirow, J. 1991. Transformative dimensions of adult learning. San Francisco: Jossey-Bass Inc.

Mezirow, J. 1998. Transformative learning and social action: A response to Inglis. Adult Education Quarterly 49(1): 70-72.

Mezirow, J. 2000a. Learning as transformation. Critical perspectives on a theory in progress. San Francisco: Jossey-Bass Inc.

Mezirow, J. 2000b. Learning to think like an adult. Core concepts of transformation theory. In Learning as transformation. Critical perspectives on a theory in progress, ed. J. Mezirow, 3-33. San Francisco: Jossey-Bass Inc.

Nexus. 2017. Lead beyond boundaries. 2017 Guidebook. Johannesburg: Centre for Leadership and Dialogue. Gordon Institute of Business Science.

Naicker, S. R. and R. Mestry. 2016. Leadership development: A lever for system-wide educational change. South African Journal of Education 36(4): 1-12.

Republic of South Africa. 2003. Broad-Based Black Economic Empowerment Act, 2003. Cape Town: The Presidency.

Republic of South Africa. 2014. Act No. 47 of 2013: Employment Equity Amendment Act, 2013. Pretoria: The Presidency.

Republic of South Africa. 2016/2017. 17th Commission for Employment Equity Annual Report. Pretoria: Department of Labour.

Soudien, C., W. Michaels, S. Mthembi-Mahanyele, M. Nkomo, G. Nyanda, N. Nyoka, S. Seepe, O. Shisana and C. Villa-Vicencio. 2008. Report of the Ministerial Committee on Transformation and Social Cohesion and the Elimination of Discrimination in Public Higher Education Institutions.

Spooner, V. S. 2018. Exploring nonformal adult learning in a business school leadership programme: A case study of the Nexus programme. Doctor of Philosophy Dissertation. University of KwaZuluNatal, Pietermaritzburg.

Taylor, E. W. 2000. Analyzing research on transformative learning theory. In Learning as transformation: Critical perspectives on a theory in progress, J. Mezirow and Associates, 285328. San Francisco: Jossey-Bass Inc.

Taylor, E. W. 2001. Transformative learning theory: A neurobiological perspective of the role of emotions and unconscious ways of knowing. International Journal of Lifelong Education 20(3): 218-236.

Taylor, E. W. 2007. An update of transformative learning theory: A critical review of the empirical research (1999-2005). International Journal of Lifelong Education 26(2): 173-194.

Van der Westhuizen, P. and H. Van Vuuren. 2007. Professionalising principalship in South Africa. South African Journal of Education 27(3): 431-446.

Vassilopoulou, J., J. P. Da Rocha, C. Seierstad, K. April and M. Ozbilgin. 2013. International Diversity Management: Examples from the USA, South Africa, and Norway. In Cultural and technological influences on global business, 14-28. IGI Global.

Walker, J. 2017. Shame and transformation in the theory and practice of adult learning and education. Journal of Transformative Education 15(4): 357-374.

Wiessner, C. A. and J. Mezirow. 2000. Theory building and the search for common ground. In Learning as transformation: Critical perspectives on a theory in progress, J. Mezirow and Associates, 329358. San Francisco: Jossey-Bass Inc. 